\title{
Thermal Decomposition of Polystyrene in the High Temperature Fabrication Technology of Hollow Microspheres
}

\author{
V.M. Dorogotovtsev, A.A. Akunets, \\ Y.A. Merkuliev, A.P. Turivnoy \\ Lebedev Physical Institute, Russian Academy of Sciences \\ Moscow, Russia
}

R. Reibold, E. Fearon, R. Cook

This paper was prepared for submittal to the Eleventh Target Fabrication Specialists' Meeting

Orcas Island, Washington

September 8-12, 1996

March 26, 1997

This is a preprint of a paper intended for publication in a journal or proceedings. Since changes may be made before publication, this preprint is made available with the understanding that it will not be cited or reproduced without the permission of the author. 


\section{DISCLAIMER}

This document was prepared as an account of work sponsored by an agency of the United States Government. Neither the United States Government nor the University of California nor any of their employees, makes any warranty, express or implied, or assumes any legal liability or responsibility for the accuracy, completeness, or usefulness of any information, apparatus, product, or process

disclosed, or represents that its use would not infringe privately owned rights. Reference herein to any specific commercial product, process, or service by trade name, trademark, manufacturer, or otherwise, does not necessarily constitute or imply its endorsement, recommendation, or favoring by the United States Government or the University of California. The views and opinions of authors expressed herein do not necessarily state or reflect those of the United States Government or the University of California, and shall not be used for advertising or product endorsement purposes. 


\title{
THERMAL DECOMPOSITION OF POLYSTYRENE IN THE HIGH TEMPERATURE FABRICATION TECHNOLOGY OF HOLLOW MICROSPHERES
}

\author{
Valeriy M. Dorogotovtsev, Alexander A. Akunets, \\ Yuriy A. Merkuliev, Alexander P. Turivnoy. \\ Lebedev Physical Institute, Russian Academy of Sciences, \\ Moscow, Russia \\ Robert Reibold, Evelyn Fearon, and Robert Cook \\ Lawrence Livermore National Laboratory \\ Livermore, CA
}

\begin{abstract}
The degree and nature of polymer degradation that occurs in the high temperature microshell formation process developed at the Lebedev Physical Institute has been examined experimentally. We find that significant mass degradation occurs during the final stages of shell formation. This manifests itself both in terms of mass loss and molecular weight degradation as measured by gel permeation chromatography. This decrease in the molecular weight may be in part responsible for the relatively fragile nature of the shells produced by this high temperature process.
\end{abstract}

\section{INTRODUCTION}

High temperature droptower techniques for producing plastic microshells with diameters in excess of $1 \mathrm{~mm}$ have been demonstrated at the Lebedev Physical Institute (LPI). ${ }^{1}$ Briefly the method involves exposing solid polymer granules containing a small fraction of a volatile organic component to a high temperature gas environment for a short time. The granules, typically composed of polystyrene, ${ }^{2}$ initially foam and then the foam coalesces to form a shell. ${ }^{3}$ The furnace temperatures typically used range from 800 to 1200 K. Generally, the shells produced are much more fragile than shells of similar size and wall thickness prepared from polystyrene by low temperature microencapsulation techniques. Since polystyrene depolymerizes at about $650 \mathrm{~K}$, one might expect some degradation in this process if the granules in fact reach the furnace temperature, and this may in part account for the increased fragility. However it also suggests that a detailed study of polymer degradation in the LPI technique is in order, and in this paper we explore this issue.

Before proceeding to our experimental study, the first question to address is how hot do the granules get as a function of time. In an effort to get a very rough (and probably upper bound) estimate of this we took as a model a spherical polystyrene granule of radius $r$ with a constant temperature (equal to the furnace temperature) boundary condition. The solution to this heat diffusion problem in a sphere is given by Crank ${ }^{4}$ and can be expressed as

$$
\begin{aligned}
& T(r, t)=T_{i}+\left(T_{f}-T_{i}\right) \times \\
& {\left[1+\frac{2 a}{\pi r} \sum_{n} \frac{(-1)^{n}}{n} \sin \left(\frac{n \pi r}{a}\right) \exp \left(-\frac{n^{2} \pi^{2} \kappa t}{c_{p} \rho a^{2}}\right)\right]}
\end{aligned}
$$

where $T_{i}$ is the initial (uniform) granule temperature, $T_{f}$ is the boundary condition (furnace) temperature, $a$ is the granule radius, $t$ is time, and $\kappa, c_{p}$, and $\rho$ are the polystyrene thermal conductivity, heat capacity, and density, respectively. Estimates for these last three quantities were taken as $0.128 \mathrm{~W} \mathrm{~m}^{-1} \mathrm{~K}^{-1}, 1.8 \mathrm{~J} \mathrm{~g}^{-1}$ $\mathrm{K}^{-1}$, and $1.05 \mathrm{~g} \mathrm{~cm}^{-3}$, respectively. ${ }^{5}$ The values for $\kappa$ and $c_{p}$ are taken at $100{ }^{\circ} \mathrm{C}$, and both increase with temperature. However since our objective at this point is only to obtain a rough estimate we have not concerned ourselves with this problem. Figure 1 displays the results of these calculations for three different values of $r$ for a $0.8 \mathrm{~mm}$ diameter granule with a $T_{i}$ of $300 \mathrm{~K}$ and a $T_{f}$ of 1000 $K$. The solid lines (left axis) show the time dependent temperature and the dashed line (right 
axis) shows the free fall distance the granule travels as a function of time. Clearly based on these crude calculations the entire granule reaches temperatures in excess of the decomposition temperature in a $1 \mathrm{~m}$ high furnace. This degree of heating is perhaps unphysical since the foamer evaporation, polymer decomposition, and thermal ablation processes will tend to suppress the temperature rise. It turns out that foamer evaporation is a minor effect, suppressing the temperature rise by no more than about $20 \mathrm{~K}$. The inclusion of polymer decomposition and ablation factors is possible, ${ }^{6}$ and will primarily cap the temperature rise at the decomposition temperature.

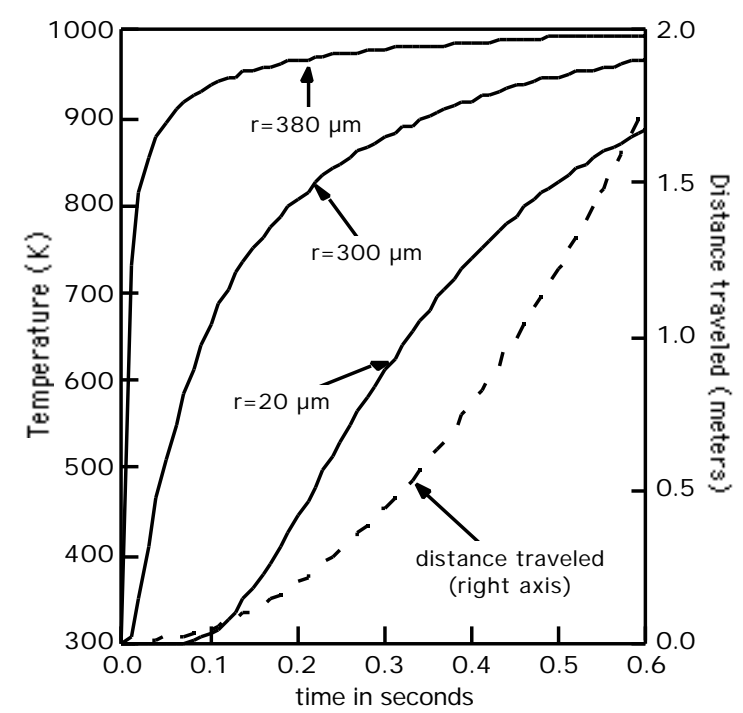

Figure 1. The solid lines (left axis) show the time dependent temperature of a polystyrene granule with radius $400 \mu \mathrm{m}$ at three different distances from the granule center which is exposed to a 1000 $\mathrm{K}$ furnace. The dashed line (right axis) shows the free fall distance the granule travels as a function of time.

In order to roughly estimate the degree of mass loss the granule might experience given the above temperature history we need to examine the relevant kinetics. To do this we used the methods developed by Burnham, et al. ${ }^{7}$ that have proved effective in modeling polymer decomposition and related mass loss at elevated temperatures. The decomposition (mass loss) rate expression is given by

$$
d x / d t=-k x(1-f x)^{m}
$$

where $x$ is the fraction of polymer mass unreacted (1-x is the fraction of mass lost) and $k$ is the temperature dependent rate constant that can be expressed in Arrhenius form as $A \exp \left(-E_{a} / R T\right)$. The $f$ factor is a numerical integration necessity and is taken as 0.99 . The values of $m, A$, and $E_{a}$ for polystyrene decomposition were determined from experimental measurements by Burnham ${ }^{8}$ to be $0.25,1.4 \times 10^{16} \mathrm{~s}^{-1}$, and $57.3 \mathrm{kcal} / \mathrm{mol}$. Given these quantities and the time dependent temperature as a function of $r$ we numerically integrated eq (2) to give the mass fraction of polymer remaining at various radial positions as a function of time in the furnace. The results for the three radial positions shown in Figure 1 are displayed in Figure 2. What is clearly seen is that there should be significant mass loss during the transit of the granule through the furnace. In fact for a $1.5 \mathrm{~m}$ furnace the granule should almost completely disappear!

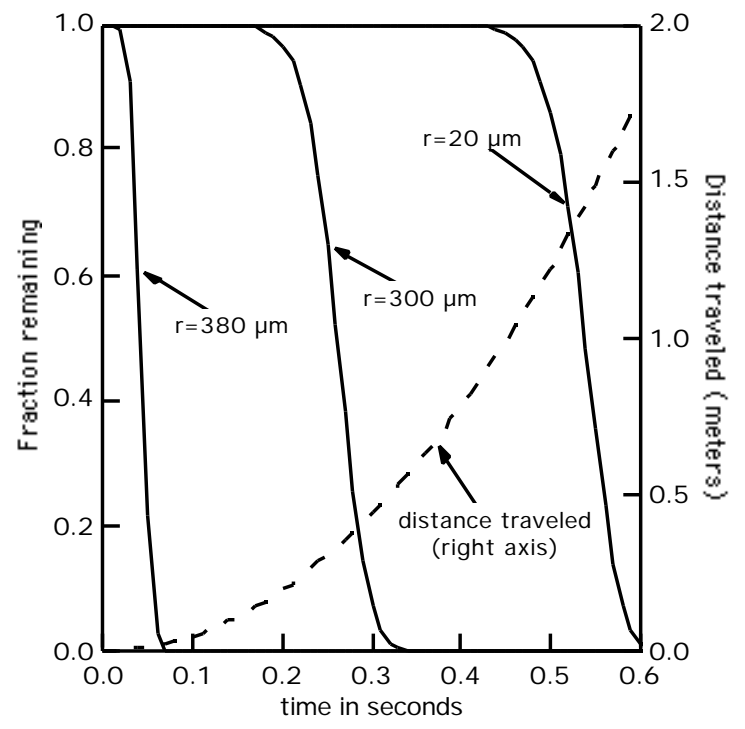

Figure 2. The solid lines (left axis) show the time dependent mass fraction remaining based on the data presented in Figure 1.

Our objective in presenting these calculations has not been to accurately determine the mass loss factors in high temperature shell formation processes, but rather to motivate our experimental investigation. The reality is that shells are produced with even higher column temperatures. The above calculations are at best very crude, for example they do not take into account that the initial $0.5 \mathrm{~m}$ of the $1.5 \mathrm{~m}$ column is generally at a temperature below the calculation temperature 
(see Figure 3); and as noted earlier they leave out a number of factors, primary among them the thermal contribution of the decomposition/ablation process to the shell temperature. But they do certainly point to chain degradation as a likely phenomena, and this experimental investigation has focused on quantifying it.

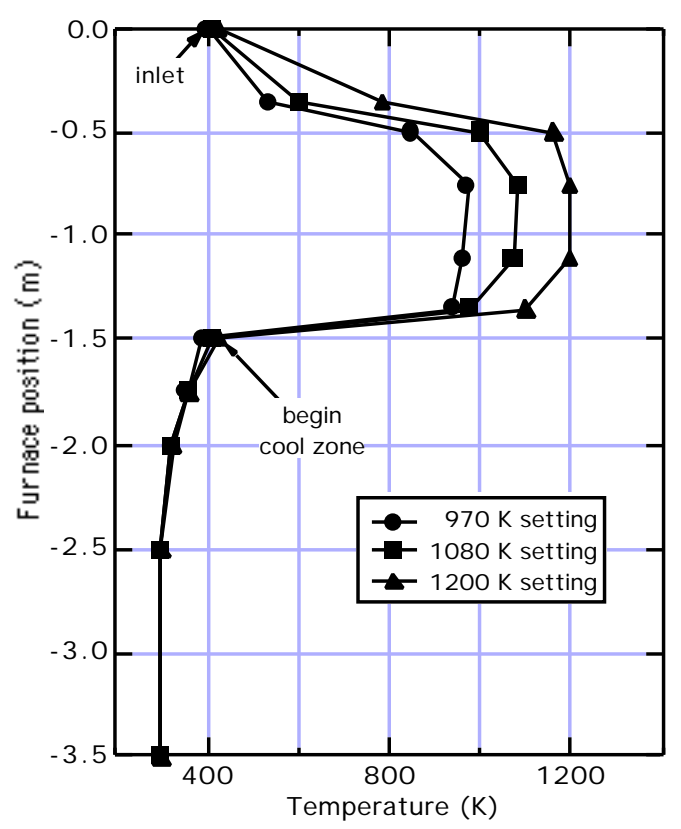

Figure 3. Shown is the measured furnace temperature profile for three different settings. The temperature of the top three $0.5 \mathrm{~m}$ sections are individually controlled. The bottom $2.0 \mathrm{~m}$ serves as the cooling zone.

Our objectives were two-fold. First we wanted to determine by direct measurement what mass loss the granules underwent during their transit through the furnace. This was accomplished by preparing a set of polystyrene granules whose masses were individually determined, dropping them individually through a furnace set at a known temperature, and then redetermining their masses. Our second objective was to determine the effect of any mass degradation on the polymer molecular weight, since a reduced molecular weight might be related to the observed shell fragility. To accomplish this objective some of the granules were prepared at the Lawrence Livermore National Laboratory (LLNL) from well characterized monodisperse polystyrene $\left(\mathrm{M}_{\mathrm{w}}=109 \mathrm{k}, \mathrm{M}_{\mathrm{w}} / \mathrm{M}_{\mathrm{n}}=1.04\right)$. This is in contrast to the suspension polymerized granules generally used at LPI that have a much broader molecular weight distribution.

\section{EXPERIMENTAL SECTION}

Polystyrene granule preparation and characterization. Using a dual orifice droplet generator, appropriately sized droplets of a 10 $\mathrm{wt} \%$ solution of polystyrene $\left(\mathrm{M}_{\mathrm{w}}=109 \mathrm{k}, \mathrm{M}_{\mathrm{w}} / \mathrm{M}_{\mathrm{n}}=\right.$ 1.04) in a 1:1 solvent mixture of methyl ethyl ketone and dichloroethane were suspended at 25 to $60{ }^{\circ} \mathrm{C}$ in an aqueous bath of $1 \%$ poly(vinyl alcohol) which served to prevent coagulation. Over a period of hours the organic solvent was lost to the bath and polystyrene beads with diameters of from 500 to $850 \mu \mathrm{m}$ were produced. The beads were then water rinsed and air dried under reduced pressure. Generally the beads were cloudy indicating the presence of many small (few micron) voids well known in microencapsulation work. ${ }^{9}$ Measurements of size and mass indicated that the internal void volume was no more than a few percent.

Thermogravimetric analysis (TGA) of these beads showed approximately an $8 \%$ mass loss before $300^{\circ} \mathrm{C}$, most of this occurring below $150{ }^{\circ} \mathrm{C}$, indicating that they contained residual small molecule components, most likely water and/or the organic solvents used. In contrast a TGA of the polystyrene material used to produce the granules showed no significant mass loss before the onset of depolymerization at about $350^{\circ} \mathrm{C}$.

The masses of 98 granules with diameters between 580 and $850 \mu \mathrm{m}$ were individually determined to the nearest $0.2 \mu \mathrm{g}$ on a Cahn microbalance. The remainder of the beads were sieved to separate them into narrow size ranges to be used in additional studies. Granules were also used in some experiments that were prepared by suspension polymerization techniques that have previously be described. ${ }^{1}$ Gel Permeation Chromatography (GPC) measurements were calibrated against monodisperse polystyrene standards.

Before use in the heated droptower, all granules were infused with a 1:5 ethyl acetate:ethanol mixture for 70 hours, resulting in an uptake of about $5 \mathrm{wt} \%$ This volatile component served as the granule foamer. ${ }^{1}$ 
Droptower Furnace. A $1.5 \mathrm{~m}$ free-fall sealed furnace with three independent temperature controlled $0.5 \mathrm{~m}$ sections was used. In all experiments the furnace atmosphere was a 1:1 Ar:He gas mixture at $0.1 \mathrm{~atm}$. Granules were introduced at the top and fell through the furnace to a $2.0 \mathrm{~m}$ cool zone at the bottom where they are recovered. There was a significant temperature gradient in the top zone with its temperature varying from about $400 \mathrm{~K}$ at the injection port to the temperature setting of the second zone, which was as high as $1200 \mathrm{~K}$. In the experiments described below, the second and third zones were kept at about $970 \mathrm{~K}, 1080 \mathrm{~K}$, or $1200 \mathrm{~K}$, with variation within the zones of as much as 20 or 30 $\mathrm{K}$. The experimentally measured temperatures in the furnace and cool zone are shown in Figure 3. In our discussion we will refer to the mean zone 2 and 3 temperatures listed above.

\section{RESULTS AND DISCUSSION}

In Figure 4 we show the measured mass recovered from the preweighed granules. Of the 98 granules dropped, 68 were recovered and measured. Granule losses were due to both difficulties with the collection of the dropped granules from the tower installation and with the transport of the dropped granules back to LLNL for mass measurement. Nine different combinations of granule sizes and furnace temperatures were used, however because of the relatively small number of samples tested for each condition no clear trends of the effect of size or temperature on mass loss could be determined. Instead we observed that most of the granules lost only the $8 \%$ volatile component that had been determined by TGA to be present in the initial granules. Only a few of the granules appeared to lose more mass. Careful examination of the post-drop granules indicated that most of those that lost only $8 \%$ of their mass had a foamlike morphology. In contrast, most of those that lost more than $8 \%$ of their mass showed indications of at least partial shell formation, generally in the form of distinct bubbles in the granule or in some cases the appearance of a deformed or collapsed shell. From these measurements alone it is impossible to tell whether the greater than $8 \%$ mass loss for some of the shells was due to polymer degradation or simply due to fracture of the initial granule.

In order to better characterize the effect of the furnace exposure on the polymer in the

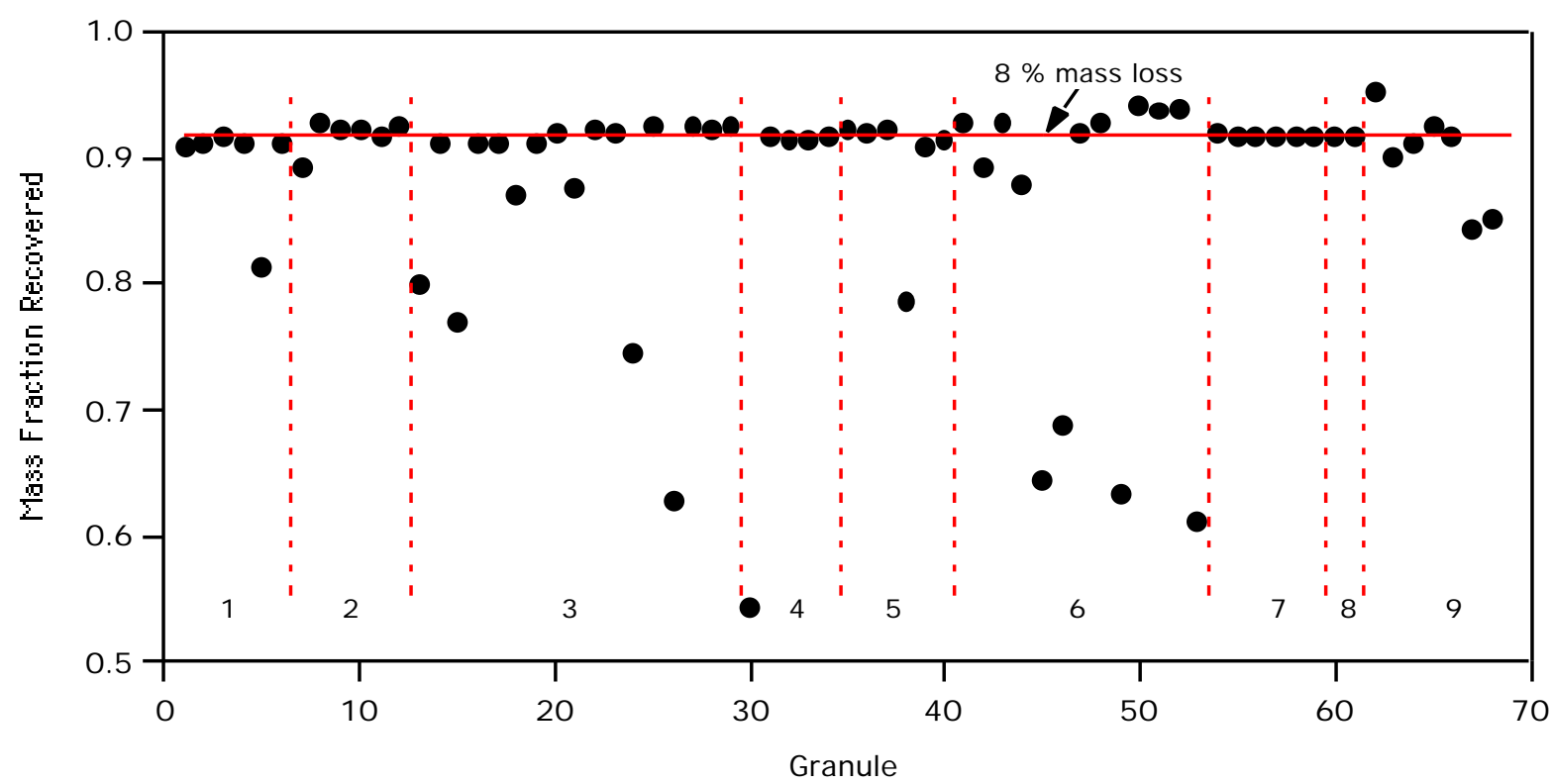

Figure 4. Shown is the fraction of granule mass recovered for each of 68 preweighed granules after dropping through the furnace. The $8 \%$ mass loss is due to volatile components in the initial granules. The vertical lines mark demarcations of different average granule size and furnace temperature, as shown in Table I. 
Table I. Preweighed granule size and temperature exposure.

\begin{tabular}{crr} 
Group & Diameter & Furnace T \\
\hline 1 & $800-850$ & 970 \\
2 & $750-800$ & 970 \\
3 & $750-800$ & 1080 \\
4 & $700-750$ & 1080 \\
5 & $660-700$ & 1120 \\
6 & $580-660$ & 1120 \\
7 & $750-800$ & 1200 \\
8 & $700-750$ & 1200 \\
9 & $580-660$ & 1200 \\
\hline
\end{tabular}

granules, GPC measurements were made . In order to obtain suitable sample sizes for analysis, several hundred granules prepared at LLNL from monodisperse polystyrene were dropped through the furnace at three furnace settings. The collected granules were then sorted into "foam-like" and "shell-like" granules. A similar process was followed with LPI produced polydisperse granules. The GPC results are shown in Table II for the two types of granules. Figures 5 and 6 show representative GPC traces for the initial, "foamlike", and "shell-like" granules for the LLNL and LPI materials, respectively. The recorded signals have been scaled for the purpose of clarifying the presentation. The important feature to note is that the initial granule foaming process does not result in any significant chain degradation whereas the shell blowing process does.

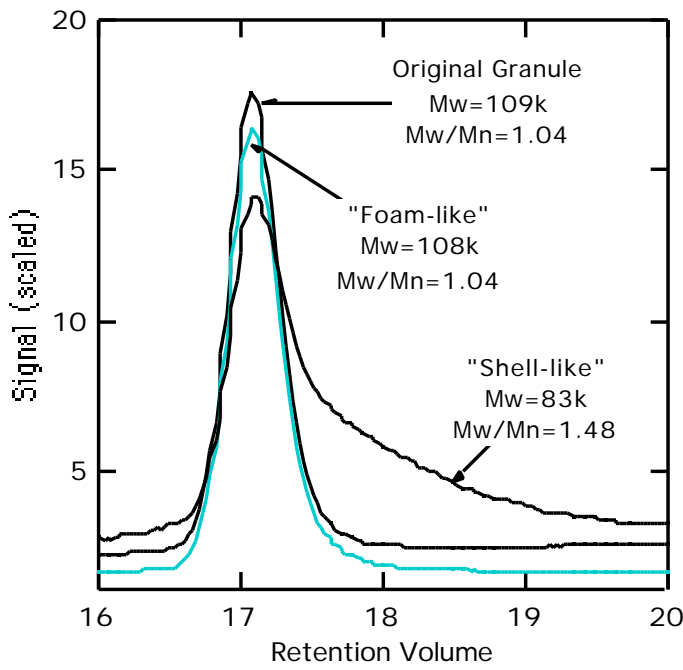

Figure 5. Shown are GPC traces for the initial, "foam-like", and "shell-like" LLNL produced granules. The furnace temperature was $1200 \mathrm{~K}$.
Clearly those granules that form shells reach higher temperatures. The complete lack of degradation upon foaming seen in the monodisperse LLNL granules indicates that these granules did not reach temperatures higher than the degradation temperature of polystyrene, about $650 \mathrm{~K}$. Those that did form shells showed degradation, and thus must have reached higher temperatures. It is worth noting that in these experiments most of the granules passed through the furnace without forming shells, instead foamlike granules were recovered. Since all granules were exposed to the same furnace environment it may be that the shell blowing process is an infrequent and random event that depends in an unknown way on the individual granules. For example, it may be necessary for some amount of the volatile foamer to be trapped and thus initiate a bubble. These more buoyant granules would then slow down, resulting in longer transit times in the furnace. In addition the formation of a shell more effectively exposes the total mass of polymer to the heat supplied by the furnace gas, thus allowing it to reach higher temperature.

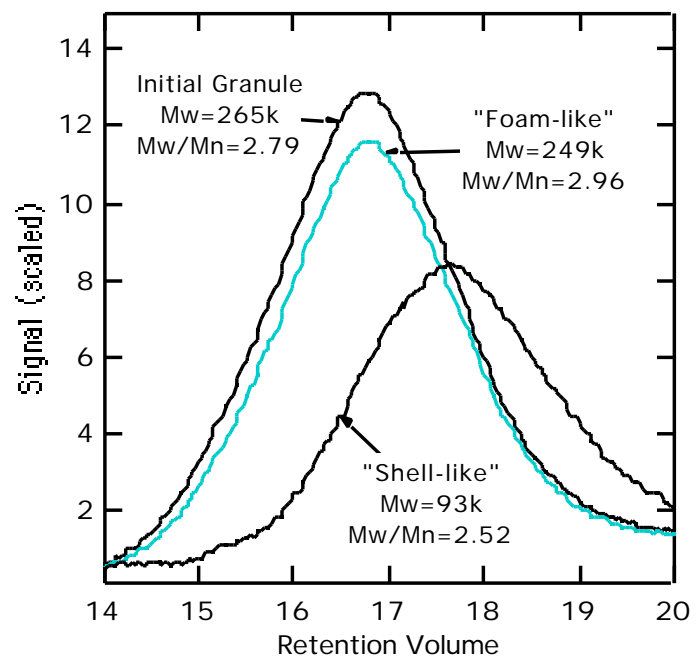

Figure 6. Shown are GPC traces for the initial, "foam-like", and "shell-like" LPI produced granules. The furnace temperature was $1080 \mathrm{~K}$.

The apparently higher degree of degradation seen in the LPI granules is likely due to a number of factors, but primary among them is that the LLNL granules were larger than the LPI granules and thus not optimum for the column conditions. The "shell-like" granules recovered from the LPI material included a number ofTable II. GPC measurement results. 


\begin{tabular}{cccrc}
\hline $\begin{array}{c}\text { Granule } \\
\text { type }\end{array}$ & $\begin{array}{c}\text { Furnace } \\
\mathrm{T}(\mathrm{K})\end{array}$ & $\begin{array}{c}\text { Granule } \\
\text { form }\end{array}$ & $\mathrm{M}_{\mathrm{W}}$ & $\mathrm{M}_{\mathrm{W}} / \mathrm{M}_{\mathrm{n}}$ \\
\hline & & & & \\
LLNL & - & initial & $109 \mathrm{~K}$ & 1.04 \\
LLNL & 970 & foam & $109 \mathrm{~K}$ & 1.04 \\
LLNL & 970 & shell & $80 \mathrm{~K}$ & 1.71 \\
LLNL & 1200 & foam & $108 \mathrm{~K}$ & 1.04 \\
LLNL & 1200 & shell & $83 \mathrm{~K}$ & 1.48 \\
LPI & - & initial & $265 \mathrm{~K}$ & 2.79 \\
LPI & 1080 & foam & $249 \mathrm{~K}$ & 2.96 \\
LPI & 1080 & shell & $93 \mathrm{~K}$ & 2.52 \\
LPI & 1200 & foam & $243 \mathrm{~K}$ & 2.39 \\
LPI & 1200 & shell & $90 \mathrm{~K}$ & 2.85 \\
\hline
\end{tabular}

actual shells while the "shell-like" granules recovered from the LLNL material did not. The failure of the LLNL granules to form shells as well as the LPI granules is certainly due in part to the fact that the shell forming process had been optimized for LPI produced granules. A reoptimization in terms of foamer composition and concentration as well as column temperature profile and granule size would be necessary to produce shells from LLNL monodisperse polystyrene granules.

\section{CONCLUSION}

We have demonstrated that the high temperature droptower techniques used at LPI for the formation of large polystyrene shells causes polymer degradation. The shell forming process involves two steps, first foaming of the initial granule and then conversion of the foam to a spherical shell. We have shown that their is no degradation associated with the first step but rather all degradation occurs in the second step.

The issue of shell fragility is a complicated one. Certainly part of the observed fragility comes from the very rapid temperature quench the molten shells undergo in passing from the hot to cold zone. This quench traps the polymer chains in nonequilibrium stressed states, and in fact it has been observed that immediately after formation the shells are extremely fragile. Room or slightly elevated temperature annealing for 24 hours results in significantly more robust shells due to chain relaxation.
The role of polymer degradation in shell fragility is clear, shorter chains result in more a brittle material. However, the solution to this problem is not straightforward, especially for large shells which require larger initial granules and thus more heating. The use of lower temperatures would certainly require longer exposure in the hot zone, and it is not clear whether this will result in more or less degradation. Improved calculations along the lines of those presented in the Introduction may shed some light on the problem. The use of higher molecular weight polymer may be a partial solution. However in a polydisperse polymer sample the shell strength may be largely controlled by the low molecular weight component, and even the $\mathrm{M}_{\mathrm{W}}=265 \mathrm{~K}$ polydisperse polymer granules have a sizable low molecular weight component, even before degradation. Thus it may make sense to more thoroughly explore the use of monodisperse polymer.

\section{ACKNOWLEDGMENTS}

Part of this work was performed under the auspices of the U.S. Department of Energy by Lawrence Livermore National Laboratory under Contract W-7405-ENG-48. The authors thank Dr. Jimmy Mays of the University of Alabama, Birmingham, for providing GPC analysis of some of the samples, and Leslie Allison of LLNL for technical assistance.

\section{REFERENCES}

1. A. A. Akunets, et al., "Laser Target Technology in Lebedev Physical Institute," in Laser Thermonuclear Targets and Superdurable Microballoons, edited by A. I. Isakov (Nova Science Publishers, Commack, NY, 1996), pp 3-33; Y. A. Merkuliev, et al., "Study of Production and Quality of Large (1-2 mm) Polystyrene Hollow Microspheres," in Hollow and Solid Spheres and Microspheres: Science and Technology Associated with Their Fabrication and Application, edited by D. L. Wilcox, et al. (Materials Research Society, Pittsburgh, PA, 1995), pp 119-124; A. A. Akunets, V. M. Dorogotovtsev, Y. A. Merkuliev, S. A. Startsev, and R. Cook, "Production of Hollow Microspheres from Solid Plastic Granules," Fusion Technol. 28, 
1781 (1995), and references therein. See also A. I. Nikitenko, S. M. Tolokonnikov, and R. Cook, "The Design of the Ballistic Furnace and Initial Microshells Formation Experiments," Fusion Technol. this issue.

2. However see V. M. Dorogotovtsev, A. A. Akunets, and Y. A. Merkuliev, "Hollow microspheres from Polyethylene Terephthalate," Fusion Technol. this issue.

3. Y. A. Merkuliev and S. A. Startsev, "Simulation of High Temperature Formation of Large (2 mm) Polystyrene Shells from Solid Granules," Fusion Technol. this issue.

4. J. Crank, The Mathematics of Diffusion, p. 86, Oxford, London (1957).

5. J. Brandup and E. H. Immergut, Polymer Handbook 2 nd ed., p. V-59 and V-60, Wiley Interscience, New York (1975).
6. Y. A. Merkuliev, unpublished work.

7. R. L. Braun, A. K. Burnham, J, G, Reynolds, and J. E. Clarkson, "Pyrolysis Kinetics for Lacustrine and Marine Source Rocks by Programmed Micropyrolysis," Energy Fuels 5, 192 (1991); A. K. Burnham, R. L. Braun, T. T. Coburn, E. I. Sandvik, D. J. Curry, B. J. Schmidt, and R. A. Noble, "An Appropriate Kinetic Model for Well-Preserved Algal Kerogens," Energy Fuels 10, 49 (1996), and references therein.

8. A. K. Burnham, unpublished results. We note that other published values for polystyrene give qualitatively the same results.

9. G. Wilemski, T. Boone, L. Cheung, D. Nelson, and R. Cook, "Prediction of Phase Separation During the Drying of Polymer Shells," Fusion Technol.

28,

1773

(1995). 


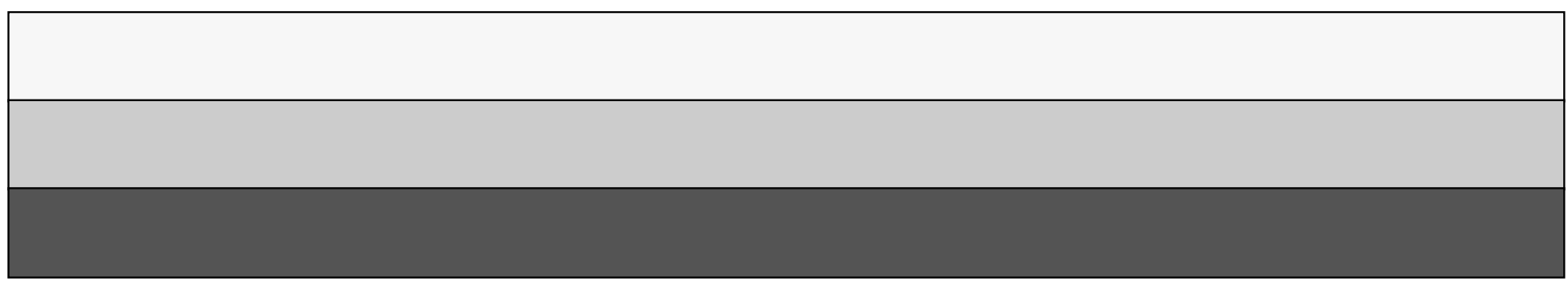

